\title{
Effect of Orientation Angle on Surface Quality and Dimensional Accuracy of Functional Parts Manufactured by Multi Jet Fusion Technology
}

\author{
Binnur Sağbaş* (i) \\ Yildiz Technical University, Mechanical Engineering Department, Istanbul, Turkey
}

\begin{abstract}
Multi Jet Fusion is one the new Additive Manufacturing method which belongs to powder bed fusion technology class and used for additive manufacturing of polymer based parts. There are restricted number of research about this developing technology. In this study, it is aimed to investigate the effect of build orientation angle on surface quality and dimensional accuracy of the printed bolts as functional parts. Samples were manufactured in two different build orientations such as 90 and 45 degrees. Surface quality and dimensional properties of the bolt tooth such as tooth height, tooth angle and distance between two teeth were inspected by optical and tactile precision measurement systems. The results were evaluated by comparing the measurement data with each other for two different sample groups and also with nominal design data. For determining the significance of the difference between two sample groups and nominal data the results were also evaluated by Student's t-test statistical analysis. The results revealed that, orientation angle had significant effect on surface roughness, tooth height and tooth angle but it didn't affect the distance between two teeth.
\end{abstract}

Keywords: Additive Manufacturing, Multi Jet Fusion, Optical Metrology, Polyamide, Precision Metrology.

\section{INTRODUCTION}

Additive Manufacturing (AM) is a novel and rapidly developing technology that builds up physical three dimensional (3D) geometries from a computer-aided 3D model (CAD) data without any usage of molds, tools or fixtures [1]. Multi Jet Fusion (MJF) is one the new AM method which works with the principle of powder bed fusion (PBF) technology and used for polymer based AM part manufacturing [2]. It was developed by HP and commercially available since 2016 [3]. MJF system consists of two main stations such as build unit and post processing unit. In build unit 3D geometry of the part generated by fusing the polymer powder together near about material melting temperature [4]. The desired geometry is defined by the fusing and detailing agents deposited by ink print heads in precise locations. After spreading the first layer of the polymer powder over the build platform, it is heated near about sintering temperature and fusing agent deposited precisely on to the powder by inkjet nozzles in accordance with 3D geometry of manufactured part. Then detailing agent is deposited near the edge of the part for inhibiting sintering. Lastly, IR energy source passes over the powder on the build pad across a line based path and sinters the areas where the fusing agent was deposited and leaves the rest of the powder unaltered. The process repeats until all parts are completed [5] Thirty million drops per second can be printed by these print heads that provide to obtain highly accurate dimensional precision compared with other technologies [6]. The geometry is built up in powder so there is no need to support structure. After building step the cooling and unpacking of the manufactured part is applied in post processing unit. These two unit system provide continuing the manufacturing process and save time [4].

Polyamide (PA) is most widely used polymer in MJF technology so as in powder bed fusion additive manufacturing techniques [5]. According to the commercial suppliers it can take different names such as PA2200 for EOS and PA12 for HP. By combining the PA powder with glass beads, carbon nano tubes, silicon carbide, aluminum and nanofibers, mechanical properties of printed parts can be increased [7]. Beside PA12 powder, PA11 and PA12 with glass beads are also suitable for the usage in MJF technique [8].

In literature studies, there are restricted number of research about MJF and they have been generally focused on mechanical properties and surface qualities. Riedelbauch et al. [3] 
studied about aging effects of reused PA12 powder on mechanical properties of MJF manufactured parts. The samples were manufactured in $\mathrm{Z}$ and $\mathrm{Y}$ orientations. They concluded that, thermal aging didn't affect the mechanical properties of the samples. Moreover, slightly higher mechanical properties were recorded for $\mathrm{Z}$ orientation than $\mathrm{Y}$ oriented parts. In another study, O'conor at al.[7] focused on the investigating mechanical properties of the PA samples manufactured by MJF technique in $\mathrm{X}, \mathrm{Y}$ and $\mathrm{Z}$ orientations. They reported that the samples exhibited isotropic behavior in terms of tensile tests while the build orientations had significant effect on flexural strength. Palma et al. [9] studied about effect of print orientation on mechanical and tribological properties of MJF manufactured PA12 samples. They built up the tensile tests samples in horizontal and vertical directions and they concluded that mechanical and tribological properties of the samples depend on print orientation.

In this study, it is aimed to define effect of orientation angle on the surface quality and dimensional accuracy of the functional parts such as bolt teeth, manufactured by MJF technology. As far as the author know, there is no detail previous study that characterizing angular, dimensional, form and roughness deviation of bolt teeth manufactured by MJF method with different orientation angle. Moreover, the study provides a comparative assessment of tactile and optical precision metrology systems for inspection of additive manufactured parts. So, it is expected that this study would be a useful reference for further studies and development of AM processes.

\section{MATERIALS AND METHODS}

\subsection{Sample Preparation}

In this study bolt samples were designed by Autodesk Fusion 360 program, converted STL file format and manufactured by HP 3D Multi Jet Fusion 4200 printer. HP 3D High Reusability PA12 powder, with $60 \mu \mathrm{m}$ particle size, $187^{\circ} \mathrm{C}$ melting point, $0.425 \mathrm{~g} / \mathrm{cm}^{3}$ powder bulk density, $1.01 \mathrm{~g} / \mathrm{cm}^{3}$ print density [10]. Samples were oriented $90^{\circ}$ perpendicularly (named as Sample-90) and $45^{\circ}$ inclined (named as Sample-45) in $\mathrm{Z}$ axis, on to the build platform. The design data and layout of the print table can be seen in Figure 1.
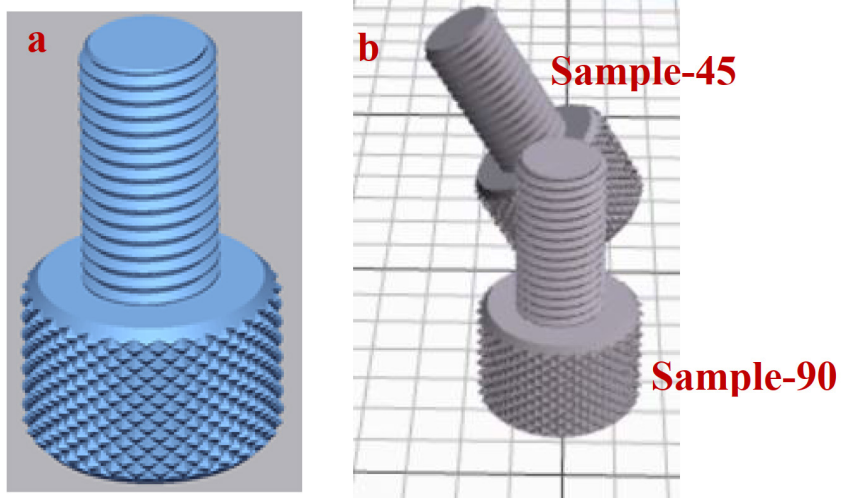

Figure 1. Design data (a) and print table layout of the samples (b)

"Balanced print mode", which provides good compromise between dimensional accuracy, mechanical properties, surface roughness and printing speed, was chosen for building up the 3D geometries [11]. All printed parts were placed with a distance of $10 \mathrm{~mm}$ from each other. After printing process, time is needed for cooling down of the built parts before taking them out. While the temperature reached about $45^{\circ} \mathrm{C}$, the built unit was taken to the post-processing station. Because the printed parts were encapsulated by powder, support structures were not necessary in the MJF process. So, just excessive powders were removed and then glass bead blasting were applied under 5 bars pressure. Before the surface measurements, the samples were washed in deionized water in ultrasonic bath for about 20 minutes and then dried in ambient condition.

\subsection{Optical and Tactile Profile Measurements}

For defining the dimensional and profile deviations of bolt teeth, Keyence VR5000 series optical scanning system was used. Dimensional measurements were taken in automatic mode with $12 \mathrm{X}$ magnification. Tooth angles and the distance between two teeth were defined by scanning the surface of the bolt in profile measurement mode with 40X magnification. Deviations of the heights, distance and angles of the teeth were defined by comparison of measured data with nominal CAD data as reference. 2D and 3D surface roughness values were define with precision scanning mode of the same system. At least three repeated measurements were taken from different regions of the samples and the mean values and standard deviations were calculated. The results were compared for two different build orientation and significance of the difference between the results were evaluated statistically.
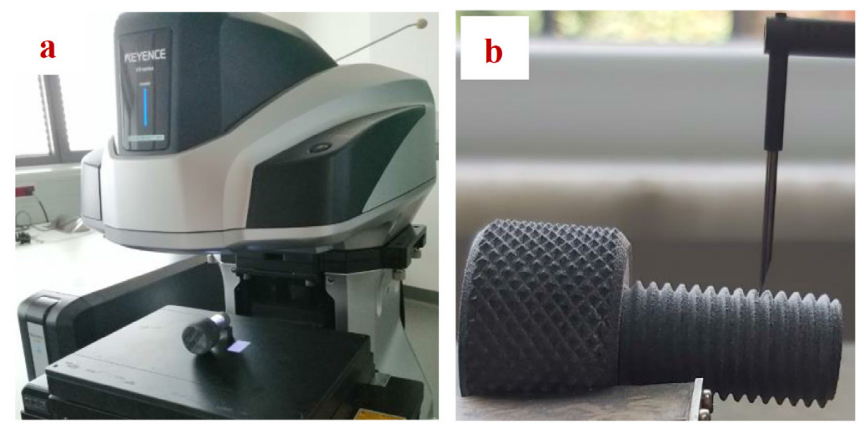

Figure 2. Optical (a) and tactile (b) measurement of the samples.

Tactile profile measurements of the samples' teeth were taken by Taylor Hobson Form Talysurf Intra. After testing different tips, chisel type tip with 1125445 code was chosen. The tip radius was $20 \mu \mathrm{m}$ and tip angle was $15^{\circ}$. Measurement evaluation length was $27 \mathrm{~mm}$ and measurement speed was $0.25 \mathrm{~mm} / \mathrm{s}$. The used optical and tactile systems can be seen in Figure 2.

\section{RESULTS AND DISCUSSION}

\subsection{Surface Roughness Results}

Roughness measurements were taken from different regions of the bolts teeth. ISO 4287 [12] 2D line Ra, Rz and ISO 
25178 [13] 3D areal Sa, Sz roughness parameters were defined. $\mathrm{Ra}$ and $\mathrm{Sa}$ represent the arithmetic mean roughness values while $\mathrm{Rz}$ and $\mathrm{Sz}$ represent the maximum height of the profile deviations such as the absolute vertical distance between the maximum profile peak height and the maximum profile valley depth along the sampling length for $\mathrm{Rz}$ and defined area for Sz. 2D and 3D average roughness values and standard deviations (SD) of the measurement results have been reported in Table 1.

Table 1.2D and 3D surface roughness values of the samples.

\begin{tabular}{|c|c|c|c|c|}
\hline \multirow{2}{*}{$\begin{array}{c}\text { Roughness } \\
\text { Parameter }\end{array}$} & \multicolumn{2}{|c|}{ Sample-45 } & \multicolumn{2}{c|}{ Sample-90 } \\
\cline { 2 - 5 } & $\begin{array}{c}\text { Av.Roughness } \\
(\mu \mathrm{m})\end{array}$ & SD $(\mu \mathrm{m})$ & $\begin{array}{c}\text { Av.Roughness } \\
(\mu \mathrm{m})\end{array}$ & SD $(\mu \mathrm{m})$ \\
\hline $\mathrm{Ra}$ & 10.714 & 0.633 & 6.508 & 0.356 \\
\hline $\mathrm{Rz}$ & 54.000 & 10.500 & 38.400 & 8.850 \\
\hline $\mathrm{Sa}$ & 20.039 & 0.333 & 19.620 & 1.180 \\
\hline $\mathrm{Sz}$ & 276.500 & 20.800 & 211.500 & 14.000 \\
\hline
\end{tabular}

Roughness results were evaluated by two-sample t-test statistical analysis for determining if there was statistically significant difference between two sample groups. Test results revealed that the difference between average surface roughness, $\mathrm{Ra}, \mathrm{Rz}$ and $\mathrm{Sz}$ values of the samples were statistically significant ( $\mathrm{p}=0.002,0.036$ and 0.021 respectively) at $\alpha=0.05$ confidence level while the difference between $\mathrm{Sa}$ parameters were not significant. The approach of the $2 \mathrm{D}$ and $3 \mathrm{D}$ roughness calculations models of surface measurement system are different. So there is no a general linear relation between $2 \mathrm{D}$ and $3 \mathrm{D}$ roughness parameters [14]. Therefore difference may occur between these two parameter groups. In overall evaluation of the roughness for both samples, all surface roughness values of the teeth on the Sample-90 were lower than Sample-45. Therefore, it can be concluded that perpendicular orientation provides better surface quality for bolt teeth. For achieving better surface quality the print part

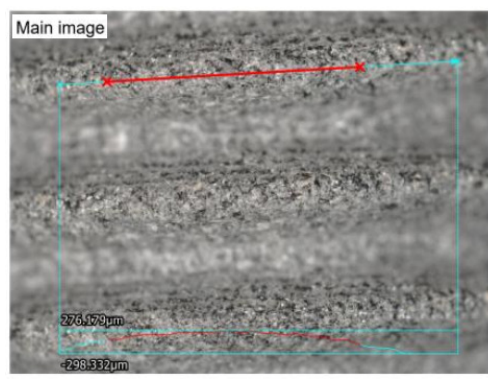

a

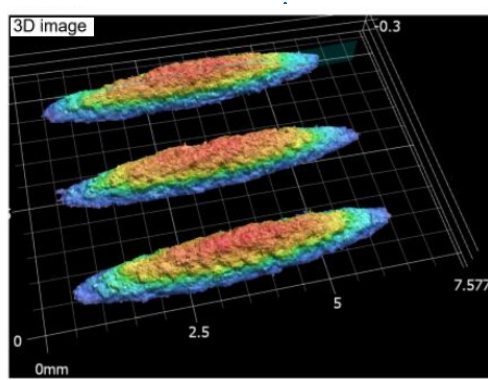

b
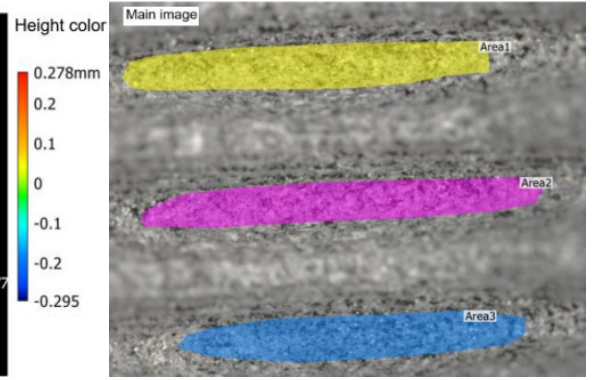

C

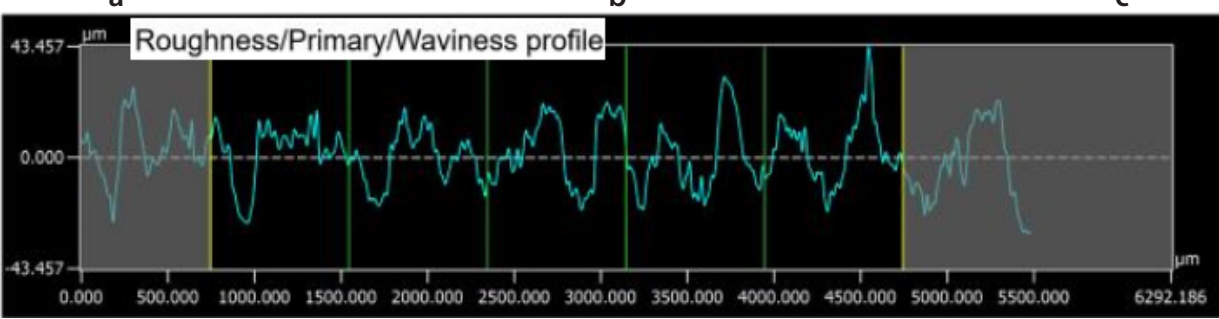

d

Figure 3. Measurement procedure and results for Sample-45; defining 2D lines on main scanned image of the teeth for investigating 2D roughness parameters (a), 3D areal surface roughness measurement image (b), definition of measurement area on main image of the teeth for investigating 3D roughness parameters (c), graph of the roughness, primary and waviness profile of the teeth (d).

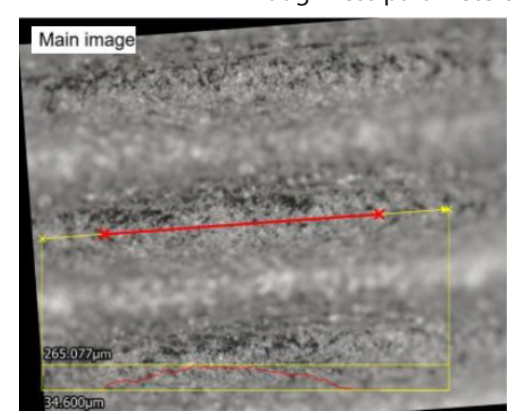

a

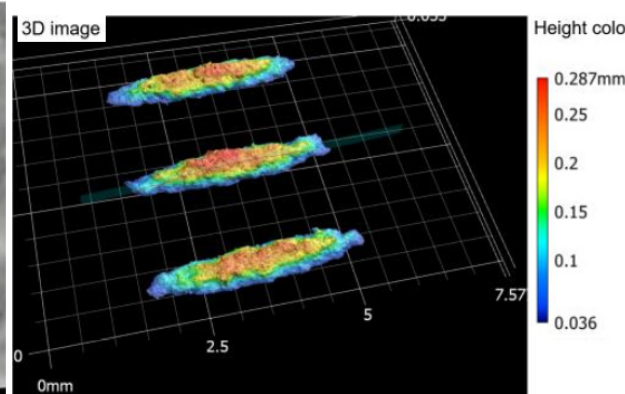

b

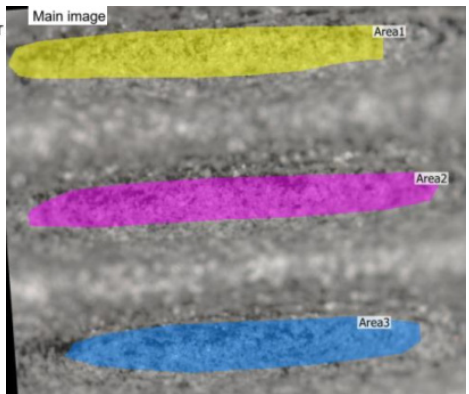

C

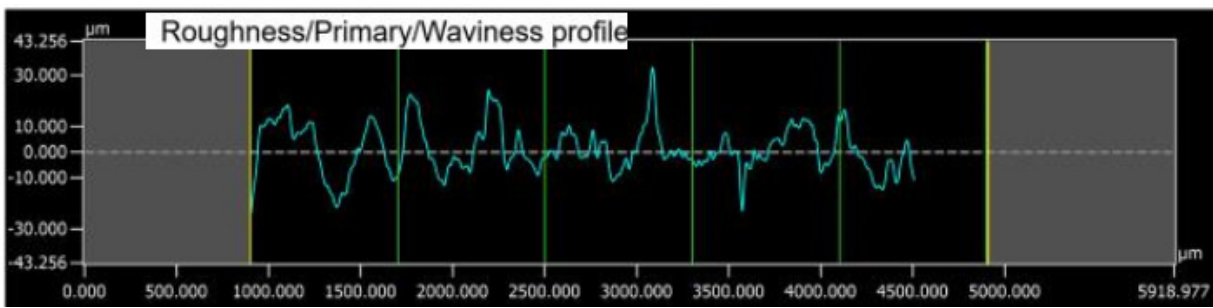

d

Figure 4. Measurement procedure and results for Sample-90; defining 2D lines on main scanned image of the teeth for investigating 2D roughness parameters (a), 3D areal surface roughness measurement image (b), definition of measurement area on main image of the teeth for investigating 3D roughness parameters (c), graph of the roughness, primary and waviness profile of the teeth (d). 
must be placed upside down in built chamber. Moreover, for avoiding stair-stepping which was defined as the geometric step formation between the successive layers and consequently a decrease in surface quality [15], the print part should be placed more than 20 degrees to the horizontal plane [16]. While the printed bolt placed perpendicularly, the teeth positions were inclined. So, better surface quality was obtained for Sample-90 than Sample-45. Measurement procedure and results can be seen in the Figure 3 and Figure 4 for Sample-45 and Sample-90 respectively.

\subsection{Dimensional Measurement Results}

Dimensional properties such as height of tooth, angle of tooth and distance between two teeth were measured by tactile and optical precision metrological systems. The nominal tooth height in CAD model was $1.11 \mathrm{~mm}$. Mean height value of Sample-45 teeth were recorded as $1.1083 \mathrm{~mm}$ while it was $1.1263 \mathrm{~mm}$ for Sample-90 teeth by tactile method. There was no significant difference between two samples tooth height and nominal value. Optical measurement data was compared with CAD model as reference geometry and mean deviations from the nominal height values were recorded as $0.1047 \mathrm{~mm}$ with SD $0.0279 \mathrm{~mm}$ and $0.1360 \mathrm{~mm}$ with SD $0.0266 \mathrm{~mm}$ for Sample-45 and Sample-90 respectively. Tooth height deviation of Sample-90 was higher than Sample-45. Measurement results can be seen in Figure 5 and Figure 6.
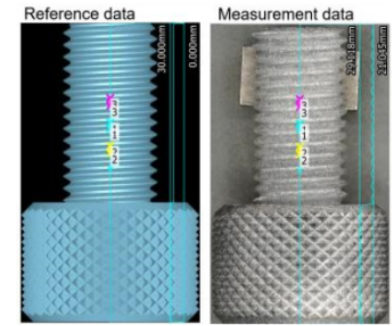

a

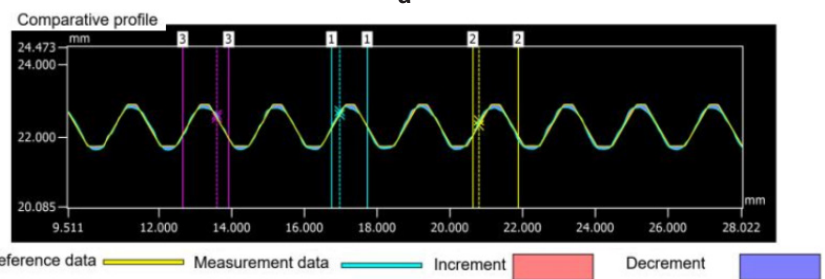

b

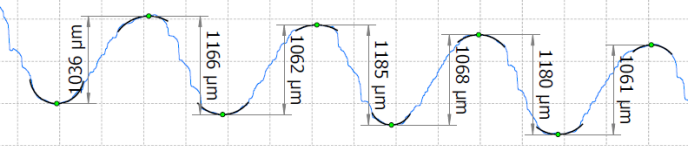

Figure 5. Comparison of the tooth height measurements for Sample-45 bolt teeth with reference CAD data (a), Comparative profile obtained by optical measurement (b), Bolt teeth profile obtained by tactile measurement (c).

For comparing the height difference of each tooth of the Sample-45 and Sample-90, the two measurement geometries, obtained by optical method, were compared to each other by defining Sample- 45 as reference data and Sample-90 as measurement data. While these two geometries
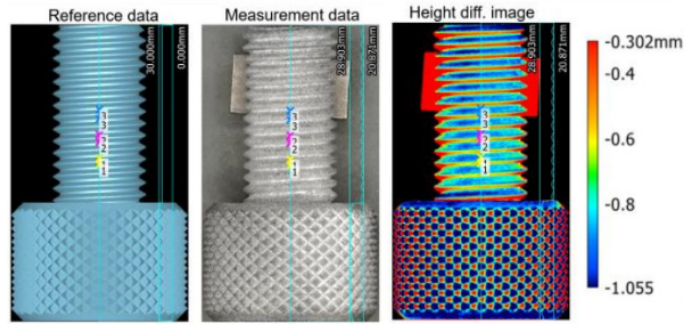

a

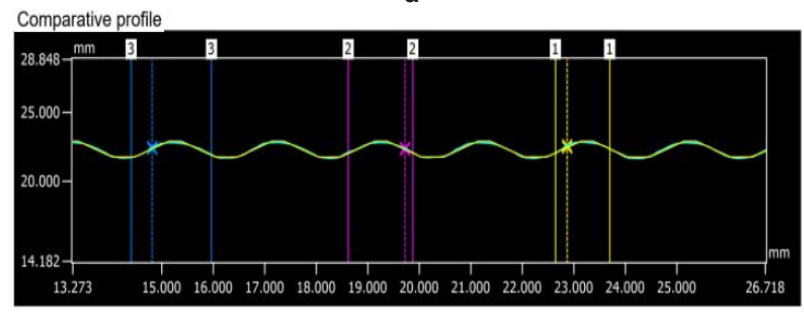

Reference data $\rightleftharpoons$ Measurement data $\rightleftharpoons$ Increment Decrement

b

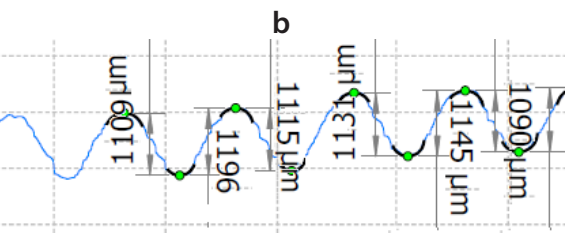

Figure 6. Comparison of the optical tooth height measurements of the Sample-90 with reference CAD data (a), Comparative profile obtained by optical measurement (b), Bolt tooth height measurements by tactile method (c).
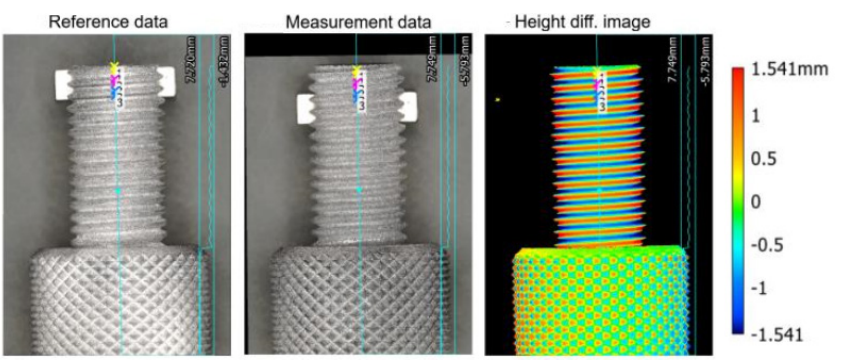

a

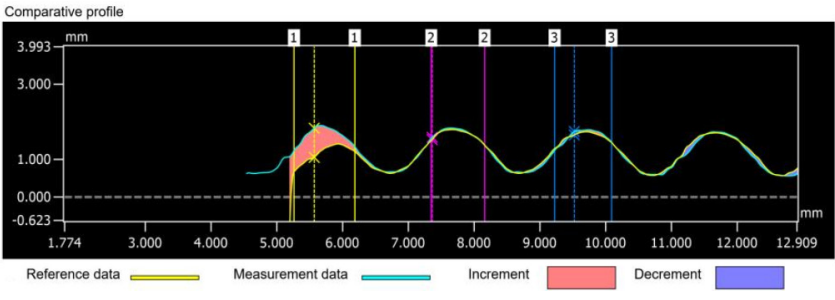

b

Figure 7. Comparison of two samples measurement data. Matching the two samples geometries (a), Comparative profile, shows the teeth height difference of Sample-90 and Sample-45 (b).

were match together, height difference image and comparative profile were obtained as in the Figure 7. Maximum difference was defined between the teeth near about the top edge and it was recorded as $0.779 \mathrm{~mm}$ which was very high and statistically significant. The difference became 0.090 $\mathrm{mm}$ and $0.063 \mathrm{~mm}$ while going from top to down of the geometries. The deviation at the top surface of Sample-90 may aroused by capillary effect which occurs when the fused polymer powder in an area acts as a fluid and tends to raise up along its borders. So, side edges of the part would be high and center of the top surface would be low. That is why top surface deviation of the Sample-90 was recorded as 
higher than the Sample-45. For improving the quality of the last layer it must be avoided to finish the printed parts with a large area to fuse [16].

Beside the height measurements, tooth angle and distance between the two teeth were also inspected for detailed evaluation of the bolt teeth profiles. Nominal tooth angle was $60^{\circ}$ while the nominal distance between two teeth was $2 \mathrm{~mm}$. The whole geometry and each tooth of the bolts were measured for defining average angular deviations and distance between each tooth precisely. Measurement procedures and results can be seen in Figure 8 and Figure 9.
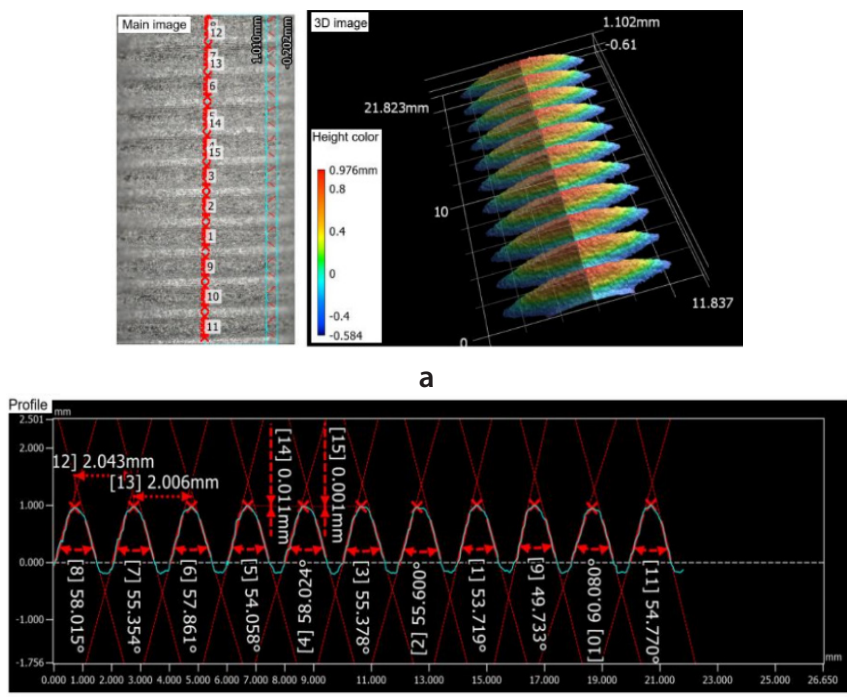

b

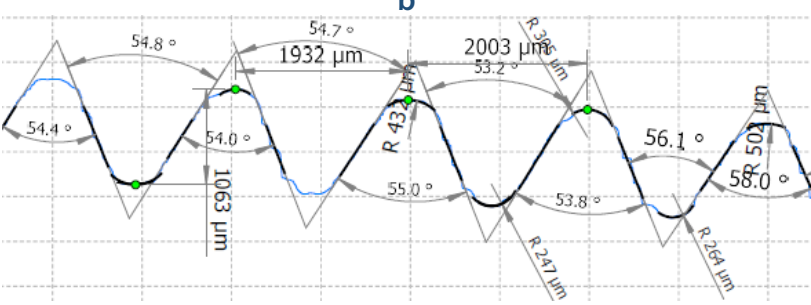

Figure 8. 3D optical tooth angle and distance measurement image of the Sample-45 (a) and measurement results (b), measurement procedure of 2D tactile tooth angle and distance measurement (c).

By optical measurement technique, average tooth angle for sample-45 was recorded as $55.69^{\circ}$ with SD $2.792^{\circ}$ where it was measured as $57.88^{\circ}$ with SD $2.219^{\circ}$ for sample-90. Tooth angle of reference CAD data was $60^{\circ}$, so the angular deviation was $4.31^{\circ}$ for sample- 45 and $2.12^{\circ}$ for sample- 90 . These differences were statistically significant with $\mathrm{p}=0.000$ for Sample-45 and $\mathrm{p}=0.010$ for Sample-90. Also the difference between two sample tooth angle values were different significantly. By tactile measurements, average tooth angle of Sample- 45 recorded as $55.32^{\circ}$ with SD $1.980^{\circ}$ and for Sample-90 as $58.009^{\circ}$ with SD $2.047^{\circ}$. These tooth angle values were statistically different from each other with $\mathrm{p}=0.000$ and $\mathrm{p}=0.038$ for Sample- 45 and Sample- 90 respectively. Moreover, tooth angle values of the both samples groups were significantly different from each other with $\mathrm{p}=0.026$.

Mean value of the distance between two teeth were measured as $2.0245 \mathrm{~mm}$ with SD $0.0262 \mathrm{~mm}$ for Sample-45 and $1.9690 \mathrm{~mm}$ with SD $0.0834 \mathrm{~mm}$ for Sample-90 by optical

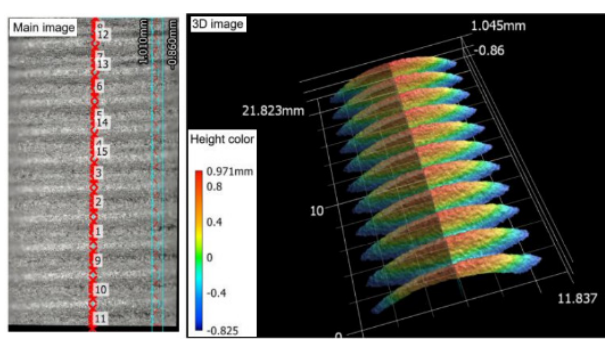

a

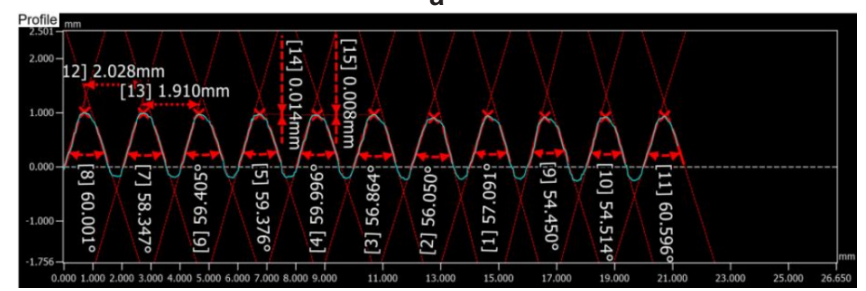

b

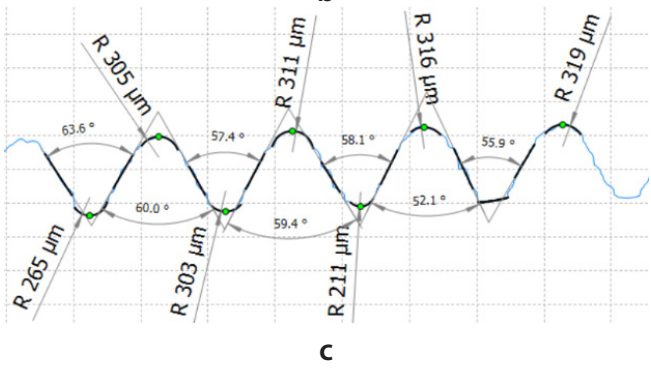

Figure 9. 3D optical tooth angle and distance measurement image of the Sample-90 (a) and measurement results (b), Measurement procedure of 2D tactile tooth angle and distance measurement (c).

method. These values were recorded as $2.0040 \mathrm{~mm}$ with SD $0.0438 \mathrm{~mm}$ for Sample-45 and $2.0680 \mathrm{~mm}$ with SD 0.0563 $\mathrm{mm}$ for Sample-90 by tactile measurements. All the distance values were statistically same with each other while the nominal reference distance value was $2 \mathrm{~mm}$ in CAD data.

\section{CONCLUSION}

In this study, effect of orientation angle on the surface roughness, tooth height, tooth angle and distance of two teeth of a bolt, manufactured by MJF process was investigated. Samples were printed in 90 and 45 degree of orientation angle. Roughness measurements and dimensional characterizations were applied by optical and tactile precision measurement systems. The results were indicated that,

- Orientation angle had significant effect on surface roughness. Perpendicular placement of the printed bolt provided better surface quality for the teeth.

- 45 degree inclined positioning provided lower tooth height difference than 90 degree.

- Tooth angle deviation of both sample groups were high and significantly different from nominal angle value of CAD data. Also, the deviation of Sample-45 was higher than Sample-90.

- Distance between two teeth was not significantly affected by orientation angle.

- Perpendicular positioning of the print part provides better surface quality and angular accuracy for bolt 
teeth manufactured by MJF process.

In conclusion, it can be said that build orientation angle affects the surface quality and dimensional accuracy of MJF manufactured parts. For further studies, experiments are continuing by trying different orientation angles for determination of optimal positioning with different process parameters.

\section{ACKNOWLEDGEMENT}

In this study manufacturing of PA12 bolt samples by MJF were supported by Form Katmanlı İmalat ve Robot Teknolojileri A.Ș.- Turkiye. Tactile surface measurements were applied in Star Teknik Elektronik Cihaz San. ve Tic. Ltd. Ști.-Turkiye. Optical measurements were taken in TU Wien, Institute for Production Engineering and Photonic Technologies, Department of Industrial Metrology and Adaptronic Systems-Austria. The author would like to thank for the supports.

\section{REFERENCES}

[1] Sagbas, B., (2020). Post-Processing Effects on Surface Properties of Direct Metal Laser Sintered AISi10Mg Parts. Metals and Materials International, 26(1): 143-153. doi:10.1007/s12540-019-00375-3

[2] Mele, M., Campana, G., Monti, G. L. (2019). Modelling of the capillarity effect in Multi Jet Fusion technology. Additive Manufacturing, 30: 100879. doi:10.1016/j.addma.2019.100879

[3] Riedelbauch, J., Rietzel, D., Witt, G. (2019). Analysis of material aging and the influence on the mechanical properties of polyamide 12 in the Multi Jet Fusion process. Additive Manufacturing, 27: 259-266. doi:10.1016/j.addma.2019.03.002

[4] Chatham, C. A., Long, T. E., Williams, C. B. (2019). A review of the process physics and material screening methods for polymer powder bed fusion additive manufacturing. Progress in Polymer Science, 93: 68-95. doi:10.1016/j.progpolymsci.2019.03.003

[5] Sillani, F., Kleijnen, R. G., Vetterli, M., Schmid, M., Wegener, K. (2019). Selective laser sintering and multi jet fusion: Process-induced modification of the raw materials and analyses of parts performance. Additive Manufacturing, 27: 32-41. doi:10.1016/j.addma.2019.02.004

[6] Morales-Planas, S., Minguella-Canela, J., Lluma-Fuentes, J., Travieso-Rodriguez, J., García-Granada, A.-A. (2018). Multi Jet Fusion PA12 Manufacturing Parameters for Watertightness, Strength and Tolerances. Materials, 11(8): 1472. doi:10.3390/ma11081472

[7] O'Connor, H. J., Dickson, A. N., Dowling, D. P. (2018). Evaluation of the mechanical performance of polymer parts fabricated using a production scale multi jet fusion printing process. Additive Manufacturing, 22, 381-387. doi:10.1016/j.addma.2018.05.035

[8] HP 3D Printing materials, (November 2019). Access date: 21.01.2020. https://www8.hp.com/h20195/v2/GetDocument.aspx?docname $=4 A A 7-1533$ ENA

[9] Palma, T., Munther, M., Damasus, P., Salari, S., Beheshti, A., Davami, K. (2019). Multiscale mechanical and tribological characterizations of additively manufactured polyamide 12 parts with different print orientations. Journal of Manufacturing Processes, 40: 76-83. doi:10.1016/j.jmapro.2019.03.004

[10] HP Data Sheet, 3D High Reusability PA 12, (March 2018). Access date: 21.01.2020. https://static1.sw-cdn.net/files/cms/materials/data-sheets/HP\%20Data\%20sheet.pdf
[11] HP MJF Handbook- General Recommendations for Printing Processes, (March 2019). Access date: 21.01.2020. https://enable.hp. com/us-en-3dprint-mjfhandbook

[12] ISO, ISO 4287:2010-07 Geometrical Product Specifications (GPS) - Surface texture: Profile method - Terms, definitions and surface texture parameters.

[13] ISO 25178-2:2012 Geometrical product specifications (GPS) — Surface texture: Areal- Part 2: Terms, definitions and surface texture parameters.

[14] Sagbas, B., Durakbasa, N. M. (2019). Profile and Areal Surface Characterization of Additive Manufacturing Polymer and Metal Parts. Proceedings of the 12th International Conference on Measurement and Quality Control - Cyber Physical Issue, 240-246. doi:10.1007/978-3-030-18177-2_22

[15] Poyraz Ö., Solakoğlu, E.U., Ören, S., Tüzemen, C., Akbulut, G. (2019). Surface texture and form characterization for powder bed additive manufacturing Journal of the Faculty of Engineering and Architecture of Gazi University, 34(3): 1653-1664. doi:10.17341/gazimmfd. 461588

[16] HP MJF Handbook- Design for Aesthetics. Access date: 21.01.2020. https://enable.hp.com/us-en-3dprint-mjfhandbook 